San Jose State University

SJSU ScholarWorks

Master's Theses

Master's Theses and Graduate Research

Spring 2017

\title{
The Moderating Effect of Gender and Tenure on the Relationship between Perceived Supervisor Support and Organizational Commitment
}

Megan Evelyn Little

San Jose State University

Follow this and additional works at: https://scholarworks.sjsu.edu/etd_theses

\section{Recommended Citation}

Little, Megan Evelyn, "The Moderating Effect of Gender and Tenure on the Relationship between Perceived Supervisor Support and Organizational Commitment" (2017). Master's Theses. 4808.

DOI: https://doi.org/10.31979/etd.3zs8-sy8q

https://scholarworks.sjsu.edu/etd_theses/4808

This Thesis is brought to you for free and open access by the Master's Theses and Graduate Research at SJSU ScholarWorks. It has been accepted for inclusion in Master's Theses by an authorized administrator of SJSU ScholarWorks. For more information, please contact scholarworks@sjsu.edu. 
THE MODERATING EFFECT OF GENDER AND TENURE ON THE RELATIONSHIP BETWEEN PERCEIVED SUPERVISOR SUPPORT AND ORGANIZATIONAL COMMITMENT

\author{
A Thesis \\ Presented to \\ the Faculty of the Department of Psychology \\ San José State University \\ In Partial Fulfillment \\ of the Requirements for the Degree \\ Master of Science
}

by

Megan Little

May 2017 
(C) 2017

Megan E. Little

ALL RIGHTS RESERVED 
The Designated Thesis Committee Approves the Thesis Titled

THE MODERATING EFFECT OF GENDER AND TENURE ON THE RELATIONSHIP BETWEEN PERCEIVED SUPERVISOR SUPPORT AND ORGANIZATIONAL COMMITMENT

by

Megan E. Little

APPROVED FOR THE DEPARTMENT OF

PSYCHOLOGY SAN JOSÉ STATE UNIVERSITY

May 2017

Dr. Howard Tokunaga Department of Psychology

Dr. Megumi Hosoda Department of Psychology

Dr. B. Lynn Ware $\quad$ Integral Talent Systems, Inc. 


\title{
ABSTRACT \\ THE MODERATING EFFECT OF GENDER AND TENURE ON THE RELATIONSHIP BETWEEN PERCEIVED SUPERVISOR SUPPORT AND ORGANIZATIONAL COMMITMENT
}

\author{
By Megan E. Little
}

The purpose of this study was to explore the extent to which the demographic variables of gender and tenure influence the strength and direction of the relationship between perceived supervisor support and organizational commitment. Responses to a 2014 organization-wide employee opinion survey from 383 employees within a computer software company were analyzed using hierarchical multiple regression. In support of previous research, results from this study lay credence to the finding that perceived supervisor support has a positive, significant relationship with organizational commitment such that individuals who felt supported by their supervisors were more likely to report higher levels of organizational commitment than individuals who did not feel supported by their supervisors. Results from this study showed that neither gender nor tenure act as moderators in the perceived supervisor support-organizational commitment relationship. Explanations and implications of these findings are discussed and avenues for future research are proposed. 


\section{ACKNOWLEDGEMENTS}

I would like to acknowledge Dr. Howard Tokunaga and Dr. Megumi Hosoda for their tireless support and contributions to my educational, professional and personal development. You have given me a wonderful gift by allowing me the privilege of becoming an SJSU I/O Psychology alumni. I will be forever grateful for this opportunity as well as the many lessons that you have bestowed upon me.

Second, I would like to acknowledge my mentor and employer Dr. B. Lynn Ware. Lynn, you have inspired me, supported me and have given me every opportunity to grow and advance my career and skill set. Your faith in me and willingness to share your knowledge have been invaluable to my success both as a student and as a professional. Thank you for making my dreams come true and for acting as the epitome of what it means to be a supportive supervisor (which greatly influenced my own organizational commitment).

Finally, I would like to thank my friends and family for their undying support over the years. Without your patience, kind words and countless hugs, I could not have achieved nearly as many of my goals. You all mean the world to me. 


\section{TABLE OF CONTENTS}

LIST OF TABLES ........................................................... viii

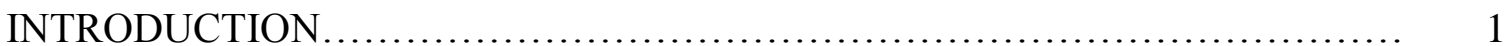

Organizational Commitment Defined..................................... 2

Predictors of Organizational Commitment.................................. 5

Perceived Supervisor Support.......................................... 7

The Relationship Between PSS and Organizational Commitment.............. 9

Previously Examined Moderators of the PSS-Organizational

Commitment Relationship...................................... 10

Purpose of the Current Study ............................................ 13

METHOD ......................................................................... 14

Participants.......................................................... 14

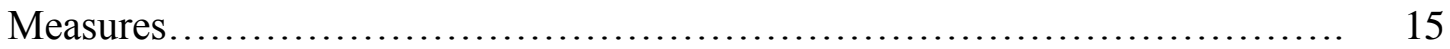

Perceived Supervisor Support.................................... 15

Organizational Commitment...................................... 16

Procedure..................................................................... 18

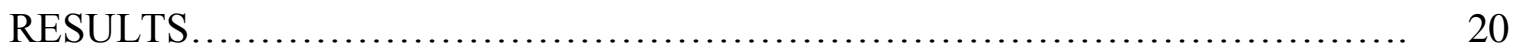

Descriptive Statistics................................................ 20

Pearson Correlations.................................................... 21

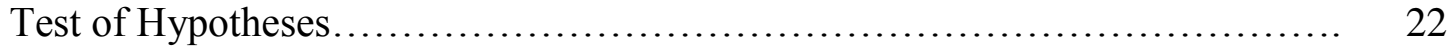

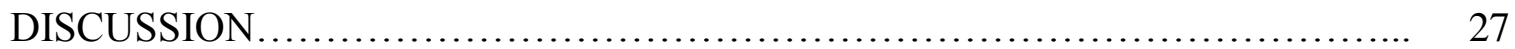


Main Findings................................................. 27

Theoretical Implications............................................. 29

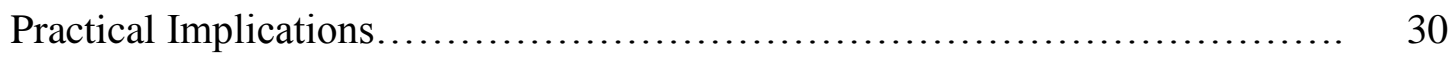

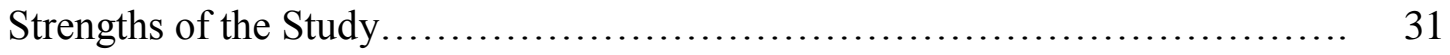

Limitations and Future Research...................................... 32

Conclusion........................................................ 34

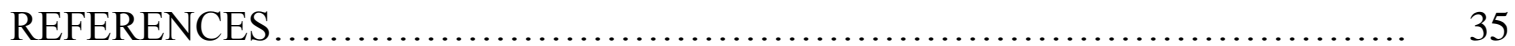




\section{LIST OF TABLES}

Table 1. Demographic Characteristics of Participants.......................... 14

Table 2. Survey Items and Factor Analysis of Perceived Supervisor Support..... 16

Table 3. Survey Items and Factor Analysis of Organizational Commitment....... 18

Table 4. Means, Standard Deviations, and Cronbach's Alpha among Studied Variables...................................................... 21

Table 5. Hierarchical Multiple Regression Correlation: Moderating Effect of Gender......................................................... 24

Table 6. Hierarchical Multiple Regression Correlation: Mode rating Effect of Tenure........................................................... 26 


\section{Introduction}

Organizational commitment is a widely researched topic that continues to intrigue researchers who seek to better understand employee behavior and create effective change in the workplace. Much interest in the topic of organizational commitment stems from its linkage to important organizational outcomes such as increased employee effort and motivation, higher job satisfaction, decreased absenteeism, lower turnover, and higher

retention (Freund, 2005; Kim \& Mueller, 2011; Klassen \& Chiu, 2011; Mathieu \& Zajac, 1990; Meyer, Stanley, Herscovitch, \& Topolnytsky, 2002; Morrow, 2011; Nägele \& Neuenschwander, 2014).

With so many beneficial outcomes associated with organizational commitment, researchers have extended a great deal of effort into understanding its antecedents. Perceived supervisor support (PSS) is one antecedent of organizational commitment that has received considerable research attention (e.g., Casper, Harris, Taylor-Bianco, \& Wayne, 2011; Dawley, Andrews and Buckley, 2008; Erickson \& Roloff, 2007). Because supervisors act as agents of the organization and spend a great deal of time in their daily interactions with employees, employee perceptions of their supervisor's supportive behavior may directly impact their commitment to an organization (Erickson \& Roloff, 2007).

Although many studies have examined the relationship between PSS and organizational commitment, no literature to date has examined the moderating effect of gender and tenure on this relationship. As past research has indicated that women place more importance on PSS than men, and that those employees with longer tenure tend to 
place less value on PSS (Ng \& Sorensen, 2008), I believed that the examination of gender and tenure as potential moderators in the PSS-organizational commitment relationship was warranted. Therefore, the purpose of this study was to examine the extent to which employee gender and tenure impact the strength and direction of the relationship between PSS and organizational commitment.

\section{Organizational Commitment Defined}

Organizational commitment has been defined as “an individual's psychological bond with an organization" (Choi, Colbert \& Oh, 2015, p. 1542). Interest in the topic of organizational commitment stems from its linkage to widely valued organizational outcomes such as job performance (Cooper-Hakim \&Viswesvaran, 2005; Meyer et al., 2002; Riketta, 2002), organizational citizenship behavior (LePine, Erez, \& Johnson, 2002; Meyer et al., 2002), and turnover (Choi, et al., 2015).

Similar to the topic of job satisfaction-how people feel about their jobs and different aspects of their jobs (Spector, 1997) —organizational commitment has been studied primarily in order to understand its antecedents and outcomes. Whereas job satisfaction focuses on employees' feelings about their jobs, organizational commitment goes a step further in that it measures employee dedication to an organization (and consequently the intent to remain). Despite the fact that both constructs have been found to be correlated with turnover intentions, for the purpose of this study I believe employee feelings about their role (job satisfaction) will not be as indicative of the aforementioned organizational outcomes as commitment to the organization will be. 
Although organizational commitment was originally believed to be a unidimensional construct, more recently it has been segmented into three distinct dimensions: affective commitment, normative commitment, and continuance commitment (Choi et al., 2015; Meyer \& Allen, 1997). Affective commitment encompasses employees' emotional attachments to the organization, normative commitment measures employees' felt obligation to remain at the organization, and continuance commitment focuses on employees' perceptions of the costs associated with terminating the relationship with the organization (Choi et al., 2015; Meyer \& Allen, 1997).

Affective commitment has been described as "the employee's state of emotional attachment to the organization" (Dawley et al., 2004, p. 513). This state of emotional attachment consists of employees identifying themselves with their organization. Employees demonstrates affective commitment when they want to stay at the organization. Normative commitment involves employees' feelings of obligation and loyalty to the organization (Allen \& Meyer, 1990; Dawley et al., 2004; Meyer \& Allen, 1991, 1997). Normative commitment differs from affective commitment in that normative commitment is derived more from a felt obligation or pressure to stay within the organization than a personal desire to stay in the organization (Dawley et al., 2004; Hackett, Bycio, \& Hausdorf, 1994; Meyer, Allen, \& Smith, 1993). The third dimension of organizational commitment is continuance commitment. As defined by Dawley et al. (2004) continuance commitment is seen "as emanating from a calculative process in which the employee accumulates interests such as pensions, seniority, social status, and 
access to social networks that bind him or her to the organization" (p. 513). In this instance, commitment is based on the presence of outside career opportunities, the state of the economy, or other personal sacrifices that could impact employees' decisions regarding whether or not to leave an organization.

For this study, I examined organizational commitment as a unidimensional construct. Although analysis of the three-component model of commitment has generally shown the dimensions to be both valid and distinct — such that the dimensions are highly correlated but unique - this study will examine organizational commitment as a unidimensional construct. In their meta-analysis, Meyer et al. (2002) noted some key issues in measuring two of the three dimensions within the three-component model. Specifically, the authors noted that more work needs to be done to fully understand how normative and continuance commitment develop. In regard to normative commitment, the authors address the similarity of this dimension to affective commitment. Compared to affective commitment, much less is known about the factors that predict normative commitment. The authors suggested this could be because normative commitment may be influenced by a variety of idiosyncratic factors, such as employee socialization experiences and organizational investments, which are difficult to measure.

When examining continuance commitment, Meyer, et al.(2002) noted that this dimension may be difficult to predict due to the fact that continuance commitment is largely determined by "side bets" individuals make when assessing their career alternatives, which are again idiosyncratic in nature. It was my hope that by looking at organizational commitment as a unidimensional construct, rather than by 
multidimensional construct, I would gain a better understanding of how the antecedent of PSS would influence employees' overall commitment to an organization.

\section{Predictors of Organizational Commitment}

Researchers have examined personal characteristics and work-related variables as antecedents in their attempts to better understand how to engender organizational commitment within the workforce. In Meyer et al.'s (2002) meta-analysis, various personal characteristics were identified as antecedents of affective organizational commitment. This research revealed demographic variables such as age, gender, education, tenure, and marital status to be weak but significant predictors of affective organizational commitment (Meyer et al., 2002). When examining age as an antecedent of affective organizational commitment, the authors concluded that there was a weak, positive association between age and affective organizational commitment such that older employees were slightly more likely to experience affective organizational commitment than younger employees $(\mathrm{r}=.15)$.

Additionally, when examined as an antecedent of affective organizational commitment, marital status was found to have a weak relationship with affective organizational commitment such that married individuals were slightly more likely to demonstrate affective organizational commitment than their non-married counterparts ( $\mathrm{r}$ $=.09$ ). Tenure was found to reflect a weak, positive relationship with affective organizational commitment such that employees with longer tenures were more likely to report higher levels of affective organizational commitment $(r=.16)$. Analysis of gender and education as potential antecedents of affective organizational commitment revealed 
that neither gender nor education significantly influenced one's reported level of affective organizational commitment $(\mathrm{r}=-.03$ and $\mathrm{r}=-.02$, respectively). Generally speaking, there is a negligible relationship when examining demographic variables as antecedents of affective organizational commitment.

Work experiences, on the other hand, have been found to be stronger predictors of affective organizational commitment than the demographic variables previously discussed. Some of the work experiences examined in the literature include transformational leadership, role ambiguity, and role conflict. Transformational leadership has been defined as "a leadership style that emphasizes change and inspiration by motivating employees through visions and values" (Hentrichet et al., 2016, p. 4). Meyer et al. (2002) found transformational leadership to be a moderate predictor of affective organizational commitment, such that the more individuals demonstrate the characteristics of a transformational leader, the higher their subordinates' reported levels of affective organizational commitment $(r=.46)$.

Role ambiguity, defined as an employee's "lack of clarity regarding the scope or nature of job responsibilities, decision authority, or relationships with others at work" (Hornung, Lampert \& Glaser, 2016, p. 489), was found to have a moderately strong, negative relationship with affective commitment such that affective commitment decreased more, the more one's role was interpreted as being ambiguous $(\mathrm{r}=-.39)$. Finally, role conflict, which has been described as "incompatible expectations directed at employees regarding the way they are supposed to perform their work roles" (Hornung et al., 2016, p. 489), was found to be yet another moderate predictor of 
affective organizational commitment, such that the more role conflict employees experienced, the less affective organizational commitment these employees were reported to experience $(\mathrm{r}=-.30)$.

Based on the results of Meyer et al.'s (2002) meta-analysis, and specifically their findings regarding the impact of work experiences as predictors of organizational commitment, I feel it is warranted to further investigate perceived supervisor support (a work experience) as an antecedent of organizational commitment. Subsequently, this study explored perceived supervisor support as a construct and provided support for its theoretical and empirical distinction from other well-researched support-based constructs.

\section{Perceived Supervisor Support}

Perceived supervisor support (PSS) has been defined as "beliefs that employees adopt concerning the degree to which their supervisor values their contribution and cares about their well-being” (Kotte \& Sharafinski, 1988, p. 100). PSS involves employees' general perceptions regarding whether or not a manager or supervisor is supportive of employee work as a whole and of the employees as individuals. As employees often spend a great deal of time with their direct managers, the manager or supervisor's investment in these employees is likely to shape their larger opinions in regards to the organization as a whole (Shanock \& Eisenberger, 2006).

PSS is a construct that has received less attention in the research literature than its related construct, perceived organizational support (POS). POS has been defined as "the generalized beliefs that employees adopt concerning the extent to which the organization 
values their contribution and cares about their well-being” (Pazy \& Ganzach, 2009, p. 1008). POS therefore encompasses employees' perceptions regarding the supportiveness of the organization as a whole, rather than the support of one single agent.

There has been some debate in the literature in regards to the distinctiveness of PSS and POS as constructs. From a theoretical perspective, PSS and POS are quite similar in that both constructs involve employees' perceptions regarding the extent to which the organization (or the supervisor as an agent of the organization) values their efforts and contributions (Erickson \& Roloff, 2007). The ways in which these constructs differ is based on one's assumptions regarding the impact of individual relationships on workplace experiences. Whereas organizations are often abstract and intangible, supervisors interact with employees more closely on a regular basis. Conflicting perspectives on the topic have revealed a disconnect between those who feel PSS should be conceptualized as a predictor of POS rather than as a standalone support construct, versus those who feel PSS needs additional attention due to the intimate and consistent nature of the supervisor-employee relationship (Maertz, Griffeth, Campbell, \& Allen, 2007).

From an empirical perspective, it has been suggested that PSS and POS are distinct constructs based on their statistically separate influences on outcome variables. For example, in contrast to the previous assumption that PSS only influences an individual's turnover cognitions by impacting the employee's perceptions of the organization itself (POS), it has been statistically found that PSS independently influences one's turnover cognitions (Maetz et al., 2007). 
In support of my attempt to examine the PSS-organizational commitment relationship, although POS has been found to have a stronger overall relationship with organizational commitment than PSS, the two have been found to be statistically distinct (Stinghalmber \& Vandenberghe, 2003). Although highly correlated, PSS and POS have been found to demonstrate different strengths in regards to their relationship with organizational commitment (Stinghalmber \& Vandenberghe). Examination of the support-organizational commitment literature has revealed that POS has a strong positive relationship with affective organizational commitment such that affective organizational commitment increases the more an employee perceives their organization as supportive (Meyer, et, al., 2002). Although the strength of the relationship has not been found to be as strong for PSS as it is for POS, PSS has still been shown to have a positive relationship with affective organizational commitment such that affective organizational commitment increases the more employees perceive their supervisors as being supportive (Dawley et al., 2008; Hutchison, 1997). Due to the theoretical and empirical distinctions between PSS and POS, I felt that additional attention to the construct of PSS was justified.

\section{The Relationship Between PSS and Organizational Commitment}

As supervisors are presumed to have a direct and regular impact on employees' training, resources and performance, it is likely that employees' beliefs in regards to supervisor support will impact the employees' psychological bond with the organization. Few studies to date have solely examined the relationship between PSS and organizational commitment as a unidimensional construct. Most studies that have 
researched the relationship between PSS and organizational commitment utilized various versions of Meyer and Allen's multidimensional three-component model (1991).

In one study, which examined relationships pertaining to work-family conflict, Casper, Harris, Taylor-Bianco and Wayne (2011) found that participants who reported higher PSS indicated experiencing higher levels of affective commitment to their organizations than those participants who felt less supported by their supervisors. Similarly, Dawley et al. (2008) found supervisor support to be a significant predictor of affective commitment in their study, which sought to examine the impact of mentoring, supervisor support and perceived organizational support on organizational commitment and job search behavior. Similarly, Çakmak-Otluoğlu (2012) found that PSS had a main effect on affective and normative commitment.

Based on these findings, it became evident that PSS has a significant positive relationship with organizational commitment, such that organizational commitment increases the more support employees feel from their supervisors. As organizations often include diverse populations of individuals, I sought to understand if the relationship between PSS and organizational commitment could be moderated by the demographic variables of gender and tenure.

\section{Previously Examined Moderators of the PSS-Organizational Commitment Relationship}

Few studies have directly examined potential moderators of the relationship between PSS and organizational commitment. The few studies that have examined moderators included both PSS and POS in the research or merely examined POS in place of PSS. I was interested in examining the moderating role of gender and tenure on the 
relationship between PSS and organizational commitment. I was unable to find any empirical studies to date that measured the extent to which gender and tenure impacted the strength and direction of the relationship between PSS and organizational commitment.

My interest in examining gender as a potential moderator of the PSSorganizational commitment relationship stems from the conceptual framework laid out in $\mathrm{Ng}$ and Sorensen's (2008) meta-analysis, which addressed the moderating effect of gender on the PSS-job satisfaction relationship. Ng and Sorensen predicted that PSS would be more valuable to female employees than to male employees (i.e. the relationship between PSS and job satisfaction would be stronger for women than for men) due to work-life balance stressors and social pressures placed on female employees, implying that female employees might be more receptive to and appreciative of PSS than their male counterparts. Although the authors did not find that gender moderated the PSS-job satisfaction relationship-perhaps as a result of ever blurring gender classifications, they encouraged further research on the influential effect of gender on PSS (Ng \& Sorensen, 2008).

$\mathrm{Ng}$ and Sorensen (2008) also sparked my interest in examining tenure as a potential moderator of the PSS-organizational commitment relationship. They argued that tenure moderated the relationship between PSS and job satisfaction such that the relationship was weaker for high-tenure employees who had been with the company for a longer period of time than for low-tenure employees who had not been with the company as long. This prediction was based on the logic that employees with longer tenures find 
support less valuable as they already have experience in their roles and sufficient coping resources, whereas newer employees find this support more valuable as they are still in need of resource allocation and in-role experience ( $\mathrm{Ng} \&$ Sorensen, 2008). Again, although their meta-analysis revealed that tenure was not a significant moderator of the PSS-job satisfaction relationship, additional research on the influence of tenure on PSS and its outcomes was encouraged.

Although Ng and Sorensen (2008) found neither gender nor tenure to be significant moderators of the relationships between PSS and job satisfaction, this could be due to the fact that job satisfaction does not delve deeply enough into an employee's fidelity to the organization. As previously mentioned, job satisfaction and organizational commitment are similar in that they assess employees' feelings regarding different aspects of their jobs. However, although job satisfaction and organizational commitment are highly correlated constructs, employees' job satisfaction can be influenced by a variety of factors that are unrelated to supervisor support such as compensation or advancement opportunities (Spector, 1997).

I wanted to explore the possibility that gender and tenure might yield moderating effects when examining the PSS-organizational commitment relationship in contrast to the PSS-job satisfaction relationship. As I found Ng and Sorensen's (2008) arguments for examining gender and tenure as moderators in their experiment to be insightful, I wanted to test these variables as moderators when exploring the relationship between perceived supervisor support and organizational commitment. Additionally, as their study was conducted as a meta-analysis, rather than as an empirical study, I felt as though 
additional research is needed to solidify the data regarding moderating effects of gender and tenure on this relationship. Thus, the following hypotheses were tested.

Hypothesis 1: Gender will moderate the relationship between perceived supervisor support and organizational commitment such that the relationship between perceived supervisor support and organizational commitment will be stronger for women than for men.

Hypothesis 2: Tenure will moderate the relationship between perceived supervisor support and organizational commitment such that the relationship between perceived supervisor support and organizational commitment will be stronger for less tenured employees than for those employees with longer tenures.

\section{Purpose of the Current Study}

The purpose of the current study was to understand the extent to which the demographic variables of gender and tenure would influence the strength and direction of the relationship between PSS and organizational commitment. Although previous research has examined demographic variables as antecedents of both organizational commitment and PSS, no study to date has examined the moderating effect of these variables on the relationship between PSS and organizational commitment. I hoped to fill the gap in the current literature by providing more insight as far as potential moderators for the direct relationship between PSS and organizational commitment. I also sought to contribute to the PSS literature by emphasizing the importance of supervisors' roles in perpetuating employee organizational commitment due to the fact that the topic of PSS has received less attention in the literature than POS. 


\section{Method}

\section{Participants}

The sample consisted of employees from a computer software company headquartered in Pleasanton, CA. Data were collected in 2014 through the use of a company-wide employee opinion survey. All full-time employees were invited to participate. Of the 512 employees, 383 respondents participated in the survey, reflecting an overall response rate of $74.80 \%$. Employee gender and tenure were collected from the company’s Human Resource Information System (HRIS). The sample consisted of $50.1 \%$ males and $49.9 \%$ females (Table 1 ). Tenure was categorized as follows: 0-90 days $(5.0 \%), 90$ days to 1 year $(25.6 \%), 1-3$ years $(35.0 \%), 3-5$ years $(15.7 \%), 5-9$ years $(9.7 \%)$ and 9 years and over $(9.1 \%)$.

Table 1

Demographic Characteristics of Participants $(N=383)$

\begin{tabular}{lcc}
\hline \multicolumn{1}{c}{ Variable } & $n$ & $\%$ \\
\hline Gender & & \\
Male & 192 & 50.1 \\
Female & 191 & 49.9 \\
Tenure & & \\
0 - 90 days & 19 & 5.0 \\
90 days - one year & 98 & 25.6 \\
1 - 3 years & 134 & 35.0 \\
3 - 5 years & 60 & 15.7 \\
5 - 9 years & 37 & 9.7 \\
9 years and over & 35 & 9.1 \\
\end{tabular}




\section{Measures}

Perceived supervisor support. For this study, I chose to utilize Kotte and Sharafinski's (1988) definition of perceived supervisor support as the "beliefs that employees adopt concerning the degree to which their supervisor values their contribution and cares about their well-being” (p. 100). In this study, PSS was measured using nine of the 58 items on the company's employee opinion survey. The items were selected based on Kotte and Sharafinski's (1988) definition. The items were then compared to the Perceived Supervisor Support Measure--Adapted scale developed by Swanberg et al. (2011) for their equivalency. The response format for these items consisted of a 5-point Likert scale which measured the extent to which employees agreed with each item. Likert scale response options were as follows: "1-Strongly Disagree”, "2-Disagree", "3-Neutral”, "4-Agree”, and "5-Strongly Agree."

A principal components analysis with varimax rotation was conducted to confirm the dimensionality of the scale. I chose to utilize varimax rotation as it minimizes the number of variables that demonstrate high loadings on a single factor. Factors with eigenvalues of 1.0 or higher were retained. Analysis of the nine PSS items revealed one factor, confirming unity of this scale. The one factor extracted accounted for $50.1 \%$ of the variance in the nine items. Factor loadings are displayed in Table 2. Cronbach's alpha was then used to estimate the reliability of the PSS scale. The scale demonstrated high internal consistency $(\alpha=.87)$. Removal of any single scale item did not reveal any increase in the scale's reliability. Individual scores on each of the items within the scale were summed and then averaged to create an all-encompassing PSS scale measure score. 
Table 2

Survey Items and Factor Analysis: PSS (N=383)

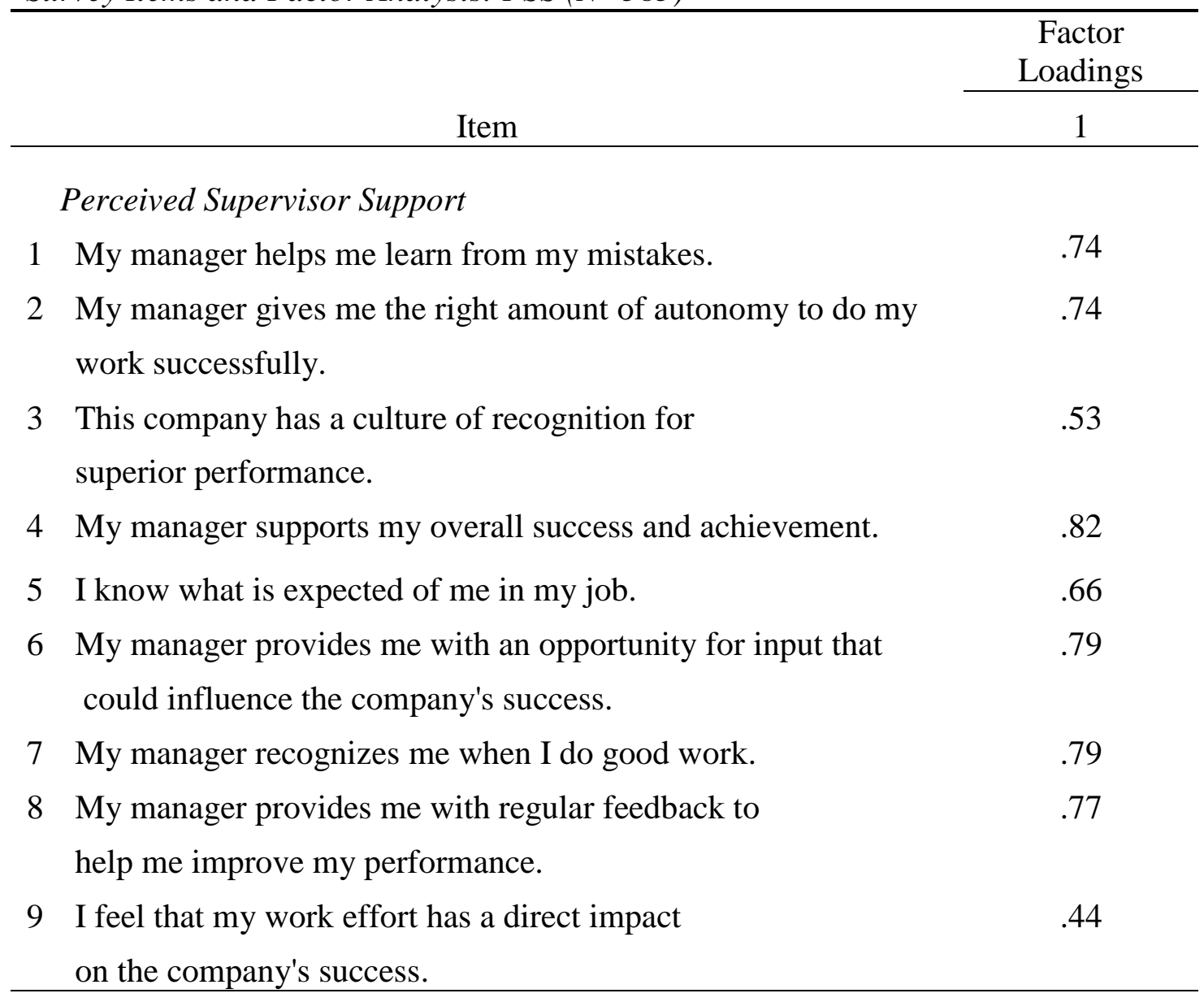

Organizational commitment. I chose to utilize Choi et al.'s, (2015) definition of organizational commitment as "an individual's psychological bond with an organization" (p. 1542). In this study, organizational commitment was measured using 10 of the 58 items on the company's employee opinion survey. The items were selected based on Choi et al.'s definition. The items were then compared to the Organizational Commitment Questionnaire (a unidimensional scale) developed by Mowday, Steers, and Porter (1979) for item equivalency. The response format for these items consisted of a 5- 
point Likert scale which measured how strongly the employees agreed with each item. Likert scale response options were as follows: "1-Strongly Disagree”, "2-Disagree”, “3Neutral”, “4-Agree”, and "5-Strongly Agree.”

As I wished to examine organizational commitment as a unidimensional construct, a principal components analysis with varimax rotation was conducted on the chosen organizational commitment scale items. Again, factors with eigenvalues of 1.0 or higher were retained. Analysis of the ten chosen organizational commitment items revealed one factor that accounted for $50.0 \%$ of the variance in 10 organizational commitment items and achieved our goal of measuring organizational commitment unidimensionally. Factor loadings are displayed in Table 3. Cronbach's alpha was then used to estimate the reliability of the organizational commitment scale. The scale demonstrated high internal consistency $(\alpha=.89)$. Removal of any single scale item did not reveal any increase in the scale's reliability. Individual scores on each of the items within the scale were summed and then averaged to create an all-encompassing organizational committment scale measure score. 
Table 3

Survey Items and Factor Analysis: Organizational Commitment $(N=383)$

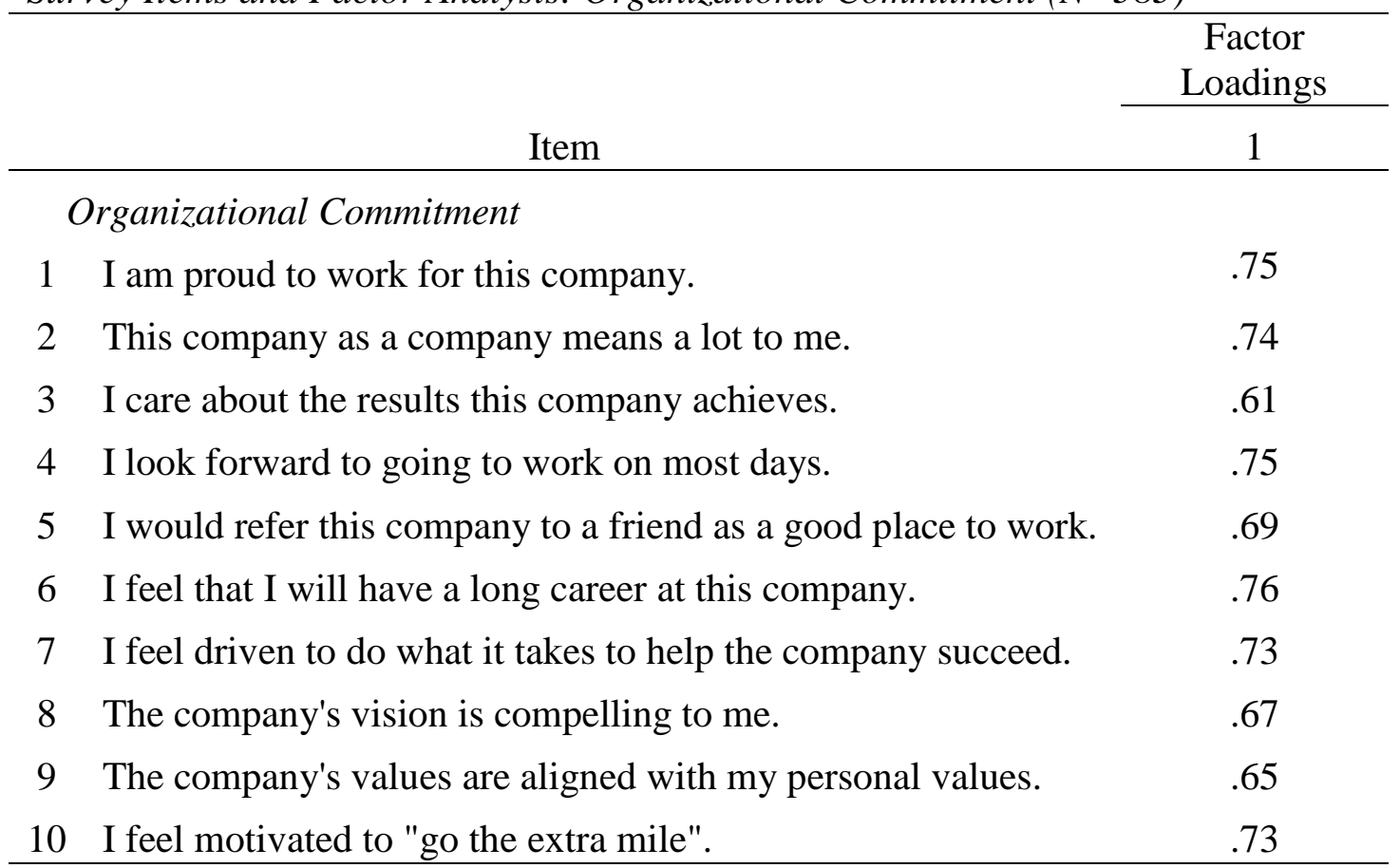

Procedure. This study was a secondary analysis of data from a 2014 employee survey conducted at a large computer software company. Permission was granted by the CEO of the third party consulting group who was contracted to distribute and analyze this survey. All eligible employees within the company were sent an email asking them to fill out an online employee survey. The email contained a link to the survey which guaranteed respondent anonymity. Anonymity was ensured as the survey was being hosted by a third-party which reported only aggregate results (for groups of 3 or larger) to the company. Employees received email messages that briefly described the purpose of the study, the time commitment involved, and appreciation for their participation. Employees who chose to participate were instructed to click on an internet link provided within the body of the message. Each respondent was provided with a unique login ID 
and password that they used to login and complete the survey. All current staff were eligible to complete the survey at the time of data collection. Data was analyzed via SPSS statistical software version 24. 


\section{Results}

\section{Descriptive Statistics}

Means, standard deviations, and Pearson correlations for the measured variables are presented in Table 4. Overall, participants reported moderate to high levels of perceived supervisor support $(M=3.94, S D=.79)$, indicating that most employees felt as though their supervisor directly valued their well-being and personal contributions. Analysis of the first moderator, gender, revealed a nearly equally split sample of male and female participants $($ males $=50.1 \%$, females $=49.9 \%$ ). Tenure, the second moderator, revealed a somewhat positively skewed distribution $(M=3.27, S D=1.30)$. As tenure was measured categorically (Table 4) these results indicate that the majority of participants held tenures between 1-5 years. In an attempt to normalize the distribution of tenure within the sample, the square root data transformation was applied. This transformation did not impact the overall results of this study and will therefore not be referenced henceforth because the original data, not the transformed data was used for analysis. Finally, participants reported high levels of organizational commitment $(M=$ $4.31, S D=.65)$, indicating that they felt psychologically bonded to the organization. 
Table 4

Means, Standard Deviations, Pearson Correlations, and Cronbach's Alphas $(N=383)$

\begin{tabular}{|c|c|c|c|c|c|c|}
\hline Variable & $\mathrm{M}$ & $\mathrm{SD}$ & 1 & 2 & 3 & 4 \\
\hline 1 Perceived Supervisor Support & 3.94 & .79 & $(.87)$ & & & \\
\hline 2 Organizational Commitment & 4.31 & .65 & $.65^{* *}$ & $(.89)$ & & \\
\hline 3 Gender & $\begin{array}{c}1=\text { Male }(50.1 \%) \\
2=\text { Female }(49.9 \%)\end{array}$ & .50 & .07 & -.02 & - & \\
\hline 4 Tenure & 3.27 & 1.30 & -.05 & -.04 & .08 & - \\
\hline
\end{tabular}

Note. $* \mathrm{p}<.05, * * \mathrm{p}<.01$

Tenure was scored as follows: 1 = "0-90 Days", 2 = "90 Days to 1 Year", 3 = "1-3 Years", 4 = "3 -5 Years", 5 = "5 -9 Years" and 6 = "9+ years"

Reliability coefficients (Cronbach's alpha) in parentheses

\section{Pearson Correlations}

As seen in Table 4, perceived supervisor support was positively related to organizational commitment $(r=.65, p<.01)$, such that the more employees perceived their supervisors as being supportive and of valuing their contributions, the more committed to the organization they were.

Gender was not significantly related to perceived supervisor support $(\mathrm{r}=.07, \mathrm{p}>$ $.05)$. Correlations were reported for the dichotomous variable gender because it is mathematically equivalent to a T-test. Therefore, being either male or female did not significantly relate to one's reported experiences of perceived supervisor support. Similarly, gender was not significantly related to organization commitment $(r=-.02, p>$ $.05)$. This again indicates that gender did not correlate with one's reported feelings of organizational commitment. 
Tenure was not significantly relate to perceived supervisor support $(\mathrm{r}=-.05, \mathrm{p}>$ .05). This finding indicates that one's longevity within an organization did not relate to one's perceptions regarding perceived supervisor support. Similarly, tenure as an independent variable was not significantly related to organization commitment $(r=-.04$, $\mathrm{p}>.05)$. Again, this finding draws the conclusion that one's tenure does not have a significant relationship with an individual's reported feelings of organizational commitment.

\section{Test of Hypotheses}

Hierarchical multiple regression (MRC) analyses were used to test Hypotheses 1 and 2. Hypothesis 1 stated that gender would moderate the relationship between perceived supervisor support and organizational commitment such that the relationship between perceived supervisor support and organizational commitment would be stronger for women than for men. PSS was entered into the regression in the first step of this analysis in order to determine whether PSS has a significant effect on one's reported feelings of organizational commitment. In the second step of this analysis, gender as an independent variable was entered into the analysis. Analysis of gender as an independent variable was intended to derive the impact of gender (being male or female) on one's organizational commitment. Finally, in the third step of the regression analysis the Gender x PSS interaction was entered in order to assess the moderating effect of gender on the PSS-organizational commitment relationship.

As shown in Table 5, to test the moderating effect of gender on the relationship between perceived supervisor support and organizational commitment, perceived 
supervisor support was entered in the first step as a predictor variable. PSS accounted for $42 \%$ of the variance in organizational commitment $\left(\mathrm{R}^{2}=.42, \mathrm{R}^{2}{ }_{\text {adj }}=.42, \mathrm{~F}(1,381)=\right.$ 279.67, $p<.001)$. This means that perceived supervisor support contributed to participants' feelings of organizational commitment, indicating that the more participant's perceived their supervisors as being supportive, the more committed they were to the organization.

In the second step of the regression analysis, gender was entered as an independent variable. Based on this regression analysis, gender was not found to have a significant effect on organizational commitment above and beyond perceived supervisor $\operatorname{support}\left(\Delta \mathrm{R}^{2}=.01, \mathrm{~F}(1,380)=3.53, \mathrm{p}=.06\right)$.

In the third step of the regression analysis, the interaction between perceived supervisor support and gender was entered. This interaction effect did not account for a significant amount of variance above and beyond the direct effects of perceived supervisor support and gender $\left(\Delta \mathrm{R}^{2}=.000, \mathrm{~F}(1,379)=.05, p>.05\right)$. Therefore, the relationship between perceived supervisor support and organizational commitment was not moderated by gender, indicating that one's gender did not significantly influence the PSS-organizational commitment relationship. Hypothesis 1 that gender would moderate the relationship between perceived supervisor support such that the relationship between perceived supervisor support and organizational commitment would be stronger for women than for men was not supported. 
Table 5

Hierarchical Multiple Regression Correlation:

Moderating Effect of Gender $(N=383)$

\begin{tabular}{|c|c|c|c|}
\hline Predictor & $\beta$ & $\mathrm{R}^{2}$ & $\Delta \mathrm{R}^{2}$ \\
\hline Step 1: Predictor Variable & & $.42 * * *$ & $.42 * * *$ \\
\hline Perceived Supervisor Support & $.65 * * *$ & & \\
\hline Step 2: Direct Effect & & $.43 *$ & .01 \\
\hline Gender & -.07 & & \\
\hline Step 3: Gender Moderator Analysis & .05 & $.43 *$ & .00 \\
\hline
\end{tabular}

Hypothesis 2 stated that tenure would moderate the relationship between perceived supervisor support and organizational commitment such that the relationship between perceived supervisor support and organizational commitment would be weaker for more tenured employees than for those employees with shorter tenures. In order to test Hypothesis 2, tenure was analyzed in the same regression order as was gender for Hypothesis 1. Therefore, PSS was entered into the regression within step one to test for the independent influence of PSS on organizational commitment, followed by tenure as an independent variable in step two, and the Tenure X PSS interaction was entered in step three as a means of testing the moderating effect of tenure in the PSS-organizational commitment relationship.

As shown in Table 6, perceived supervisor support was entered in the first step as a predictor variable. PSS accounted for $42 \%$ of the variance in organizational commitment $\left(\mathrm{R}^{2}=.42, \mathrm{R}^{2}\right.$ adj $\left.=.42, \mathrm{~F}(1,381)=279.67, p<.001\right)$. This means that perceived supervisor support contributed to participant's feelings of organizational 
commitment, indicating that participants who perceived their supervisors as being more supportive are more likely to express higher levels of organizational commitment.

In the second step of the regression analysis, tenure as an independent variable was entered. Tenure alone did not account for a significant amount of variance above and beyond perceived supervisor support $\left(\Delta \mathrm{R}^{2}=.00, \mathrm{~F}(1,380)=.007, \mathrm{p}>.05\right)$. Therefore, tenure did not have a significant incremental effect on organizational commitment.

In the third step of the regression analysis, the interaction between perceive supervisor support and tenure was entered. This interaction effect did not account for a significant amount of variance above and beyond the direct effects of perceived supervisor support and tenure $\left(\Delta \mathrm{R}^{2}=.00, \mathrm{~F}(1,379)=1.24, p>.05\right)$. Therefore, the relationship between perceived supervisor support and organizational commitment was not moderated by tenure. Hypothesis 2 that tenure would moderate the relationship between perceived supervisor support and organizational commitment such that the relationship between perceived supervisor support and organizational commitment would be stronger for less tenured employees than for those employees with longer tenures was not supported. 
Table 6

Hierarchical Multiple Regression Correlation:

Moderating Effect of Tenure $(N=383)$

\begin{tabular}{lccc}
\multicolumn{1}{c}{ Predictor } & $\beta$ & $\mathrm{R}^{2}$ & $\Delta \mathrm{R}^{2}$ \\
\hline $\begin{array}{l}\text { Step 1: Predictor Variable } \\
\text { Perceived Supervisor Support }\end{array}$ & $.65 * * *$ & $.42 * * *$ & $.42 * * *$ \\
Step 2: Direct Effect \\
$\begin{array}{l}\text { Tenure } \\
\text { Step 3: Tenure Moderator Analysis }\end{array}$ & .00 & $.42 *$ & .00 \\
& & $.43 *$ & .01 \\
\hline Notes: $* p<.05, * * p<.01, * * * p<.001$ & & \\
\hline
\end{tabular}




\section{Discussion}

This study explored the extent to which the demographic variables of gender and tenure would impact the strength and direction of the relationship between perceived supervisor support and organizational commitment. Although many studies have examined the relationship between PSS and organizational commitment, no literature until now has examined the moderating effect of gender and tenure on this direct relationship. The exploration of this relationship provides valuable insights for the important workplace variables of perceived supervisor support and organizational commitment and therefore their beneficial outcomes because this study attempted to answer previously researched relationships.

\section{Main Findings}

Hypothesis 1 predicted that gender would moderate the relationship between perceived supervisor support and organizational commitment such that the relationship between perceived supervisor support and organizational commitment would be stronger for women than for men. This hypothesis was not supported as gender was not found to moderate the strength and direction of the relationship between perceived supervisor support and organizational commitment.

One possible explanation for the finding that gender did not moderate the strength and direction of the relationship between perceived supervisor support and organizational commitment could be the result of cultural shifts in regards to the definition of and roles associated with gender. In recent years, gender has become a more fluid construct as opposed to more the traditional, western conceptualizations of gender which are strictly 
binary (clear distinction between male vs. female) (Ng and Sorensen, 2002).

Additionally, as women take on larger roles within the workforce, stereotypical male and female domestic responsibilities have shifted to promote a more equitable distribution of work place and household duties. This shift in the gender denominations and roles may account for the non-significant effect of gender as a moderator in the PSS-organizational commitment relationship. This could be because gender is a vastly more blended and varying construct than previously perceived. Because of this more recent ambiguous conception of gender, it becomes difficult to distinguish clear differences between male and female subgroups. Ultimately, as the distinction between the two genders can be argued to be unclear, the PSS-organizational commitment relationship did not differ as a function of gender.

Hypothesis 2 predicted that tenure would moderate the relationship between perceived supervisor support and organizational commitment such that the relationship between perceived supervisor support and organizational commitment would be stronger for less tenured employees than for those employees with longer tenures. Again, this hypothesis was not supported as tenure was not found to moderate the relationship between perceived supervisor support and organizational commitment. This suggests that an employee's length of time spent working for an organization did not influence the relationship between perceived supervisor support and organizational commitment.

This finding could be the result of employees needing different types of support from their supervisors depending on their tenure within the organization. The results have revealed a strong relationship between PSS and organizational commitment. The finding 
that tenure was a non-significant moderator in the relationship between the two suggest that the PSS-organizational commitment relationship is strong, regardless of one's tenure. Although specific types of employee support needs may differ as a result of tenure, the need for PSS in general does not. For example, whereas newer employees might value support from their supervisor because of allocation of specific training and resources, more tenured employees may still value and desire support from their supervisors, but this support might be directed towards different goals such as career development efforts and understanding of work-life balances. The variation in employee needs as a result of their length of time spent within the organization could explain the finding that tenure was not a moderator in the PSS-organizational commitment relationship.

\section{Theoretical Implications}

This study found a significant positive relationship between perceived supervisor support and organizational commitment, which implies that the more supportive staff perceive their supervisors to be, the more likely that these staff members are to report feeling committed to the organization as a whole. Consistent with past literature, PSS was found to have a significant positive relationship with organizational commitment such that one's perceptions regarding perceived supervisor support directly influence one's reported commitment to the organization (Casper, Harris, Taylor-Bianco, \& Wayne, 2011; Dawley, Andrews, \& Buckley, 2008; Erickson \& Roloff, 2007).

Consistent with Meyer et al.'s 2002 meta-analysis, a second theoretical implication of this study derives from the finding that neither gender nor tenure were found to have significant direct correlations with organizational commitment. This study 
seems to provide support for their finding that the relationship between demographic variables (specifically gender and tenure) and organizational commitment is essentially negligible.

Finally, similar to Ng and Sorensen's (2002) finding that neither gender or tenure moderated the PSS-job satisfaction relationship, this study also found that neither gender nor tenure were significant moderators of the PSS-organizational commitment relationship. Just as $\mathrm{Ng}$ and Sorensen suggested in their meta-analysis, perhaps the focus on demographic differences should be of less concern than more pertinent work experiences such as resource allocation or performance management processes.

\section{Practical Implications}

Practical implications of this research pertain to the need for HR managers to structure their support behaviors around factors other than demographic. As organizational commitment is associated with a variety of desirable organizational outcomes such as decreased turnover and improved performance, investment in optimizing the supervisor-employee support relationship should become a staple directive of HR managers (Freund, 2005; Kim \& Mueller, 2011; Klassen \& Chiu, 2011; Mathieu \& Zajac, 1990; Meyer, Stanley, Herscovitch, \& Topolnytsky, 2002; Morrow, 2011; Nägele \& Neuenschwander, 2014). A focus on improving supervisor-employee support relationships should be implemented such that more discretionary effort is made to ensure that employees are feeling valued and supported by those individuals who they directly report to. These relationships and support perceptions could have a long-lasting impact 
on the employees' overall feelings towards the organization. Open communication and regular check-ins to assess support perceptions should be prioritized.

The gender and tenure of direct reports should not influence the approach a supervisor takes when attempting to provide support to his or her staff. Supervisors should not treat their employees differently because of their identified gender category. Both male and female employees should receive equitable levels of PSS regardless of their gender classification. The actual support behaviors of the supervisor to staff as a whole should be given more attention than gender distinctions between a supervisor's direct reports. Similarly, when taking tenure into consideration, supervisors should again focus more on the efficacy of their ability to provide PSS rather than the demographic breakup of their staff. As mentioned previously, although an employee's exact support needs (e.g., training, resources, tools) may change over time as a result of their tenure and experience, the need for PSS exists regardless of how long the employee has been working at the organization.

\section{Strengths of the Study}

A major strength of this study is its unique contribution to the support and commitment literature. This study was able to provide support for perceived supervisor support as an antecedent to organizational commitment, which consequently provides the academic community with further insights into how to foster employee organizational commitment. Additionally, this study provided valuable insight in regards to the use of demographic variables as moderators of the PSS-organizational commitment relationship. As a result of this study, we have provided support for the academic need to spend less 
focus on more superficial demographic variables and focus more time exploring new possible moderators to this relationship.

\section{Limitations and Future Research}

Despite the unique contributions to the psychological literature, this study had limitations that should be addressed. First, it must be noted that this study was crosssectional in nature and therefore provides only a snapshot of what the PSS-organizational commitment relationship might look like on a larger scale. Additionally, only one company from one region was included, therefore, the issue of generalizability should be taken into question. The results of this study may not be pertinent to other countries and/or cultures with non-western ideals in regards to roles within the home and the workplace. In order to resolve this limitation, future research should seek to explore this relationship in a longer term, longitudinal study that captures data from a larger variety of sources and cultures.

A second limitation of this study is that the survey items created by the company itself. Although steps were taken to ensure the reliability of the scale, further researchers should test these relationships through the use of other organizational commitment and perceived supervisor support scales in order to gain a more comprehensive understanding of their relationship. Additionally, future research should consider the inclusion of measuring non-binary gender roles within their research in order to widen the demographic net of their sample.

A third limitation of this study is that tenure was categorized with redundant or overlapping increments (i.e. "0 - 90 Days" and "90 Days to 1 Year”). This overlap in 
tenure categorizations could have caused confusion on the part of the respondents and led to less accurate breakdowns of actual employee tenure demographic groupings. In order to resolve this limitations, future research should attempt to measure tenure with a more distinctly categorized scoring breakdown.

Future research should also consider exploring other potential moderators in the PSS-organizational commitment relationship that focus on work experience rather demographic differences. This could provide greater insight in regards to what workplace experiences influence the impact of support and add to organizational fidelity. For example, based on Meyer et al.'s (2002) finding that the workplace experience of role ambiguity has a moderately strong negative relationship with affective organizational commitment, future researchers should explore the extent to when one's clarity regarding their job role influences the PSS-organizational commitment relationship.

I would also recommend future researchers consider broadening their research when collecting support-specific data. It may be valuable to explore other forms of support, such as support from one's peers, family members, team members, coworkers, or spouse to gain a better understanding of how support from various sources impacts one's workplace commitment and retention. For example, Ng and Sorensen (2008) explored both PSS and PCS (perceived coworker support) in their meta-analysis so that they might gain a better understanding of the effect of various support perceptions on work experiences. Future researchers should explore PSS, PCS and other alternative forms of support in order to gain a more comprehensive understanding of how support 
from those with whom an employee interacts with regularly influences their work experiences.

Finally, future researchers should examine support needs throughout the employee lifecycle. Our finding that tenure did not moderate the relationship between perceived supervisor support and organizational commitment demonstrates that employees throughout all stages of their career value support from their supervisors. However, the differences in the types and delivery of this support may differ dependent on one's tenure and experience.

\section{Conclusion}

It was the goal of this study to explore the extent to which one's gender and organizational tenure moderate the relationship between perceived supervisor support and organizational commitment. Although neither gender nor tenure were found to moderate this relationship, this study has provided support for the need for continued research in the support-commitment literature. Perceptions regarding supervisor support behaviors could have long-term consequences for organizations in regards to their employees' organizational commitment and consequently their performance and turnover intentions. The results of this study emphasize the importance of training supervisors to demonstrate effective support behaviors if organizations wish to retain loyal and committed employees. 


\section{References}

Çakmak-Otluoğlu, K. Ö. (2012). Protean and boundaryless career attitudes and organizational commitment: The effects of perceived supervisor support. Journal of Vocational Behavior, 80, 638-646.

Casper, W. J., Harris, C., Taylor-Bianco, A., \& Wayne, J. H. (2011). Work-family conflict, perceived supervisor support and organizational commitment among Brazilian professionals. Journal of Vocational Behavior, 79, 640-652.

Choi, D., Oh, I., \& Colbert, A. E. (2015). Understanding organizational commitment: A meta-analytic examination of the roles of the five-factor model of personality and culture. Journal of Applied Psychology, 100, 1542-1567.

Cooper-Hakim, A., \& Viswesvaran, C. (2005). The construct of work commitment: Testing an integrative framework. Psychological Bulletin, 131, 241-259.

Dawley, D., Andrews, M., \& Bucklew, N. (2008). Mentoring, supervisor support, and perceived organizational support: What matters most? Leadership \& Organization Development, 29, 235-247.

Dawley, D., Stephens, R., \& Stephens, D. (2004). Dimensionality of organizational commitment in volunteer workers: Chamber of commerce board members and role fulfillment. Journal of Vocational Behavior, 67, 511-525.

Erickson, R. A., \& Roloff, M. E. (2007). Reducing attrition after downsizing. International Journal of Organizational Analysis, 15, 35-55.

Freund, A. (2005). Commitment and job satisfaction as predictors of turnover intentions among welfare workers. Administration in Social Work, 29, 5-21.

Hackett, R. D., Bycio, P., \& Hausdorf, P. A. (1994). Further assessments of Meyer and Allen's (1991) three-component model of organizational commitment. Journal of Applied Psychology, 79, 15-23.

Hentrich, S., Zimber, A., Garbade, S. F., Gregersen, S., Nienhaus, A., \& Petermann, F. (2016). Relationships between transformational leadership and health: The mediating role of perceived job demands and occupational self-efficacy. International Journal of Stress Management, 24, 34-61.

Hornung, S., Lampert, B., \& Glaser, J. (2016). Dealing with organizational double binds: Three-way interactive effects of role stressors and coping on worker exhaustion. Psychological Reports, 118, 487-509.

Kim, S.W., \& Mueller, C. W. (2011). Occupational and organizational commitment in different occupational contexts: The case of South Korea. Work and Occupations, $38,3-36$. 
Klassen, R. M., \& Chiu, M. M. (2011). The occupational commitment and intention to quit of practicing and pre-service teachers: Influence of self-efficacy, job stress, and teaching context. Contemporary Educational Psychology, 36, 114-129.

Kotte, J. L., \& Sharafinski, C. E. 1988. Measuring perceived supervisory and organizational support. Educational and Psychological Measurement, 48, 10751079.

Lepine, J. A., Erez, A., \& Johnson, D. E. (2002). The nature and dimensionality of organizational citizenship behavior: A critical review and meta-analysis. Journal of Applied Psychology, 87, 52- 65.

Maertz, C. P., Griffeth, R. W., Campbell, N. S., \& Allen, D. G. (2007). The effects of perceived organizational support and perceived supervisor support on employee turnover. Journal of Organizational Behavior, 28, 1059-1075.

Mathieu, J. E., \& Zajac, D. (1990). A review and meta-analysis of the antecedents, correlates, and consequences of organizational commitment. Psychological Bulletin, 108, 171-194.

Meyer, J. P., \& Allen, N. J. (1991). A three-component conceptualization of organizational commitment. Human Resource Management Review, 1, 61-89.

Meyer, J. P., Allen, N. J., \& Smith, C. A. (1993). Commitment to organizations and occupations: Extension and test of a three-component conceptualization. Journal of Applied Psychology, 78, 538-551.

Meyer, J. P., \& Allen, N. J. (1997). Commitment in the workplace: Theory, research, and application. Thousand Oaks, CA: Sage Publications.

Meyer, J. P., Stanley, D. J., Herscovitch, L., \& Topolnytsky, L. (2002). Affective, continuance, and normative commitment to the organization: A meta-analysis of antecedents, correlates, and consequences. Journal of Vocational Behavior, 61, $20-52$.

Morrow, P. C. (2011). Managing organizational commitment: Insights from longitudinal research. Journal of Vocational Behavior, 79, 18-35.

Mowday, R. T., Steers, R. M., Porter, \& Lyman W. (1979). The measurement of organizational commitment. Journal of Vocational Behavior, 14, 224-247.

Ng, T. W., \& Sorensen, K. L. (2008). Toward a further understanding of the relationships between perceptions of support and work attitudes: A meta-analysis. Group \& Organization Management, 33, 243-268.

Nägele, C., \& Neuenschwander, M. P. (2014). Adjustment processes and fit perceptions as predictors of organizational commitment and occupational commitment of young workers. Journal of Vocational Behavior, 85, 385-393. 
Pazy, A., \& Ganzach, Y. (2009). Pay contingency and the effects of perceived organizational and supervisor support on performance and commitment. Journal of Management, 35, 1007-1025.

Riketta, M. (2002). Attitudinal organizational commitment and job performance: A metaanalysis. Journal of Organizational Behavior, 23, 257-266.

Shanock, L. R., \& Eisenberger, R. (2006). When supervisors feel supported: Relationships with subordinates' perceived supervisor support, perceived organizational support, and performance. Journal of Applied Psychology, 91, 689695.

Stinglhamber, F., \& Vandenberghe, C. (2003). Organizations and supervisors as sources of support and targets of commitment: A longitudinal study. Journal of Organizational Behavior, 24, 251-270.

Spector, P. E. (1997). Job Satisfaction: Application, assessment, causes, and consequences. Thousand Oaks, CA: Sage Publications, Inc.

Swanberg, J. E., McKechnie, S. P., Ojha, M. U., \& James, J. B. (2011). Schedule control, supervisor support and work engagement: A winning combination for workers in hourly jobs? Journal of Vocational Behavior, 79, 613-624. 